\title{
味覚センサを用いた医薬品の服用性の総合評価
}

\author{
内田享弘
}

\section{Comprehensive Evaluation of Palatability for Commercial Medicine by Taste Sensing System}

\author{
Takahiro Uchida \\ Faculty of Pharmaceutical Sciences, Mukogawa Women's Univeresity; \\ 11-68 Koshien 9-Bancho, Nishinomiya, Hyogo 663-8179, Japan.
}

(Received August 31, 2013)

\begin{abstract}
The bitterness of 10 basic medicines was evaluated using a multichannel taste sensor (Intelligent Sensor Technology). Three variables were obtained from the taste sensor data: sensor output $(\mathrm{S})$, the change of membrane potential caused by adsorption, corresponding to aftertaste (C), and the ratio $\mathrm{C} / \mathrm{S}$. These variables were used to predict an estimated bitterness score in multiple regression analysis. There was correlation between the bitterness score predicted by the taste sensor and the score obtained by human gustatory sensation. The method showed quantitative predictability for the evaluation of bitterness. Secondly, bitterness intensities of eight $\mathrm{H}_{1}$-antihistamines were assessed by comparing the Euclidean distances between the drug and water using taste sensing system Astree II ( $\alpha$-MOS). Two sensors were ultimately selected as best suited to bitterness evaluation, and the data obtained from the two sensors depicted the actual taste map of the eight drugs. Also the bitterness masking efficiency of epinastine hydrochloride with acesulfame potassium was successfully predicted. Finally, Vesicare ${ }^{\circledR}$ tablets, whose main component is solifenacin succinate, are known to be extremely bitter. Recently, Vesicare ${ }^{\circledR}$ orally disintegrating tablets (ODTs), which contain a salting-out taste-masking system, have appeared on the market. To evaluate the effect of crushing on the bitterness of the tablets, Vesicare ${ }^{\boxplus}$ ODTs and conventional Vesicare ${ }^{\circledR}$ tablets (CTs) were crushed either heavily or lightly. The bitterness scores of sample solutions were predicted using taste sensor. The lightly crushed ODT was predicted to be less bitter than CT. When tablets must be crushed, it is strongly recommended that ODT be crushed gently.
\end{abstract}

Key words — multichannel taste sensor; evaluation of bitterness; acesulfame potassium; bitterness masking; Vesicare ${ }^{\circledR}$ tablet

\section{1. はじめに}

「良薬口に苦し」という言葉から，医薬品の味と 言えば，内服薬である散剤などの苦味を想定するで あろう。キニーネなどの苦味を持つアルカイドは毒 のシグナルとしての意義を持ち, 多くの医薬品はな んらかの苦味を持っている場合が多い.しかしなが ら, 一口に医薬品といっても, 内服薬, 苦味アミノ 酸を含む経腸栄養剂, 漢方薬（生薬成分を含む）,

ドリンク剤など医薬品は多様な服用性，苦味を呈す る。それらはときとして患者のコンプライアンスを 大きく損ねる.したがって，薬物自体や剤形として

The author declares no conflict of interest.

武庫川女子大学薬学部（T663-8179 兵庫県西宮市甲子

園九番町 11-68)

e-mail: takahiro@mukogawa-u.ac.jp

本総説は, 日本薬学会第 133 年会シンポジウム S30302 で発表した内容を中心に記述したものである.
の医薬品の苦味を含めた味を正しく評価し，それら を数值化することは，服用し易い医薬品をつくると いう観点から重要である。一方, 薬物の苦味を知る ためのヒトによる官能試験は, 安全性の情報が不足 している開発初期の薬物においては実施不可能であ り，上市後の薬物であっても倫理的な観点から簡単 ではない，ヒトによる官能試験に頼らない薬物の定 量的な苦味予測は，製剤研究者にとつて達成しなけ ればならない大きな課題であると言える。これを解 決し得るのが味覚センサ (味認識装置) である.

近年, 味覚センサ (味認識装置) を使用した定量 的な苦味評価が注目を集めている。われわれは 2000 年より, 味認識装置 TS-5000Z（インテリジエ ントセンサーテクノロジー）を用いて，（1）多くの 塩基性医薬品・アミノ酸製剂・漢方薬・ドリンク剤 等について苦味の定量化について検討し, ${ }^{1-10}$ セ セン 
サ測定值を用いて苦味強度を予測するシステムを構 築している.

最近は，（2） 8 種類の $\mathrm{H}_{1}$ 受容体拮抗薬をモデル 薬物とし，インセント社センサに加えて電子味覚シ ステムASTREE（アルファ・モス）を使用し，苦 味・酸味の呈味評価や，その苦味抑制の予測などよ り製剂設計に直結する情報をセンサで評価した. ${ }^{11-13)}$

さらに，（3）医療現場で行われている簡易懸濁法 を口腔内崩壊錠に施した場合の粉砕力の強さが苦味 強度に与える影響についても味覚センサの利用が有

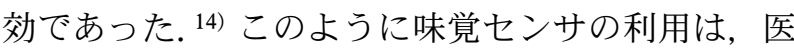
薬品の開発，製剂設計，医療現場で使用時の製剤の 苦味評価を可能にする点で利用価值があると考える.

2. インテリジェントセンサーテクノロジー社の 味認識装置を使用した塩基性薬剤・アミノ酸の苦味 予測 ${ }^{1-10)}$

インテリジェントセンサーテクノロジー社の味認 識装置は, 基本五味, 酸味, 塩味, 甘味, 苦味, そ して旨味に対して特異的に応答するセンサプローブ を使用する，使用されるセンサは，人工脂質と可塑 剂からなる人工脂質膜が取りつけられており，対象 となる呈味物質がこの人工脂質膜と静電的，あるい は疎水的な相互作用によって反応し，膜電位の変化 を生じさせる，その電位差がセンサ出力として検知 され，味の評価のために解析される.

複数のセンサデー夕を用いて苦味を予測する場 合，予測苦味強度（Estimated bitterness score）Y は 次式で表現できる。

$$
\mathrm{Y}=\mathrm{aX}_{1}+\mathrm{bX}_{2}+\mathrm{cX}_{3}+\cdots \mathrm{zX}_{\mathrm{n}}
$$

ただし $\mathrm{X}_{\mathrm{n}}$ は説明変数（Explanatory variable）で ある。

本検討では，唾液に相当する標準溶液，測定試料 の電位を測定し，測定値をそれぞれVr, Vs とし た. 測定試料の電位測定後, 再び標準溶液に戻って センサ測定した電位 $\mathrm{Vr}^{\prime}$ を測定した。（Vs-Vr）を

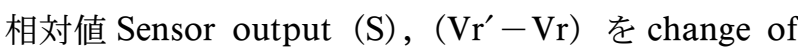
membrane potential caused by adsorption (CPA) (C) , CPA/Sensor output を(C/S) と表現し，これ ら 3 つを説明変数として利用した。 これら測定手順 については Fig. 1 にまとめた.

相対值（S）は，薬物溶液を口に含んだ直後の苦 味の強さに相当し, CPA は薬物溶液を口に含み, 吐き出し後に残存するいわゆる後味としての苦味の

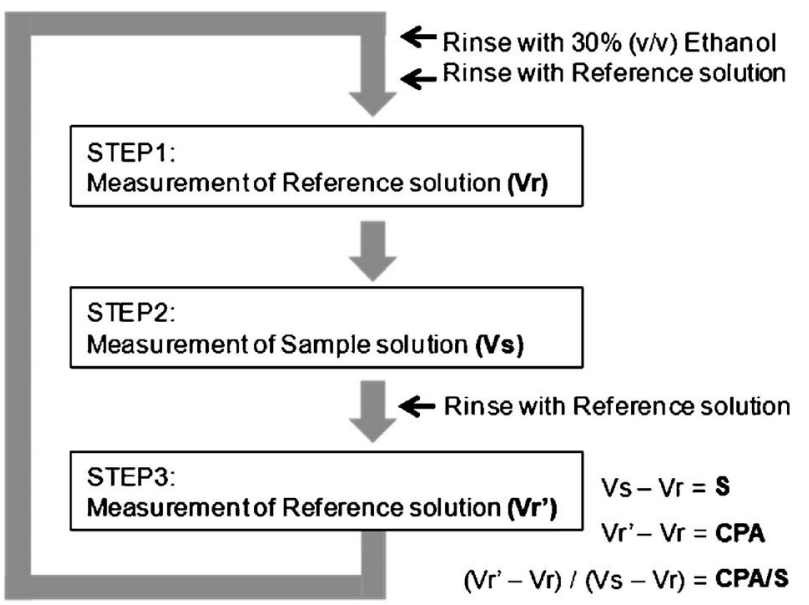

Fig. 1. Measurement Procedure of Taste Sensing

強さに相当する，苦味を有する多くの塩基性薬剤に ついて，苦味特定的なセンサの上記測定デー夕を利 用して単回帰又は重回帰分析を行うことで，ヒト官 能試験による苦味強度の予測が可能であった。

Figure 2 に，その例として臨床で比較的苦味が強 いとされている，構造が異なる 10 種の塩基性薬物 について 2 チャネルと 4 チャネルの $\mathrm{C} / \mathrm{S}$ 関数を利 用して重回帰分析を行い最適化した結果を示した. ${ }^{2)}$ 横軸はヒト官能試験で得られた苦味強度，縦軸はモ デル式から得られた苦味強度の推定值を示した．図 中の $\mathrm{Y}=\mathrm{X}$ の直線上にポイントが近ければ近いほど 官能值とセンサに予測值のずれが小さいことを示し ている. 回帰の相関係数は $\mathrm{r}=0.822$ と比較的良好 であった。ささらに服用性が悪いとされている抗菌薬 についても，苦味応答のセンサ出力を単回帰分析を 用いて多くの抗菌薬の良好な予測性を確認してい る. ${ }^{3)}$ 抗菌薬の中で最も苦味が強かったマクロライ ド系のクラリスロマイシンについては，各種濃度の クラリスロマイシン懸濁溶液に比較して, 苦味マス キングの工夫が施されたドライシロップ製剤の苦味 が 99\%達成されている事実を苦味センサを用いた

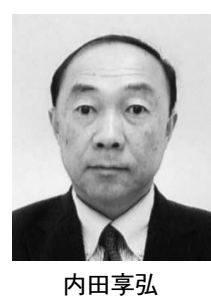

昭和 58 年九州大学薬学部卒業, 同 63 年同大薬剂学教室助手, 平成 4 年米国 カンサス大学留学, 帰国後病院で研修 後, 平成 8 年武庫川女子大学・薬学部 助教授を経て同 14 年同大臨床製剂学教 室教授，現在に至る。平成 9 年日本薬 剂学会旭化成製剂学奨励賞受賞, 日本 薬剤学会評議員，センサによる製剤評 価, 微粒子製剂, 注射剤が専門。 


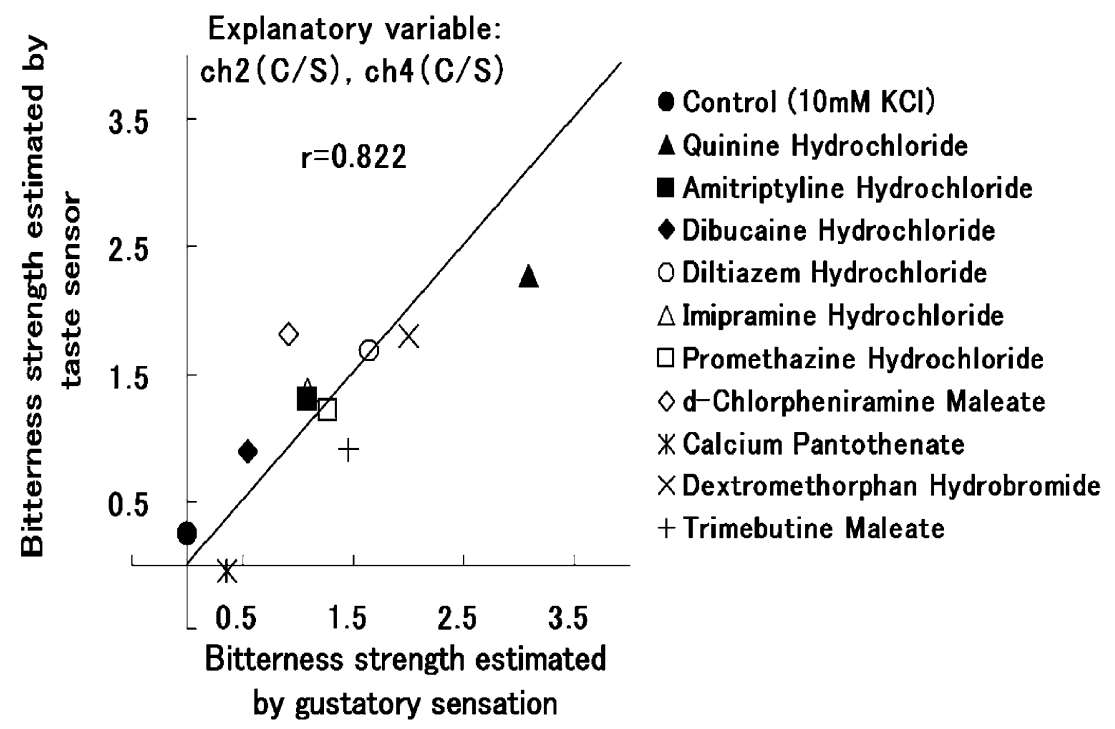

Fig. 2. Multiple Regression Analysis of 10 Drugs Using C/S Data as Explanatory Variables for Channels 2 and 4

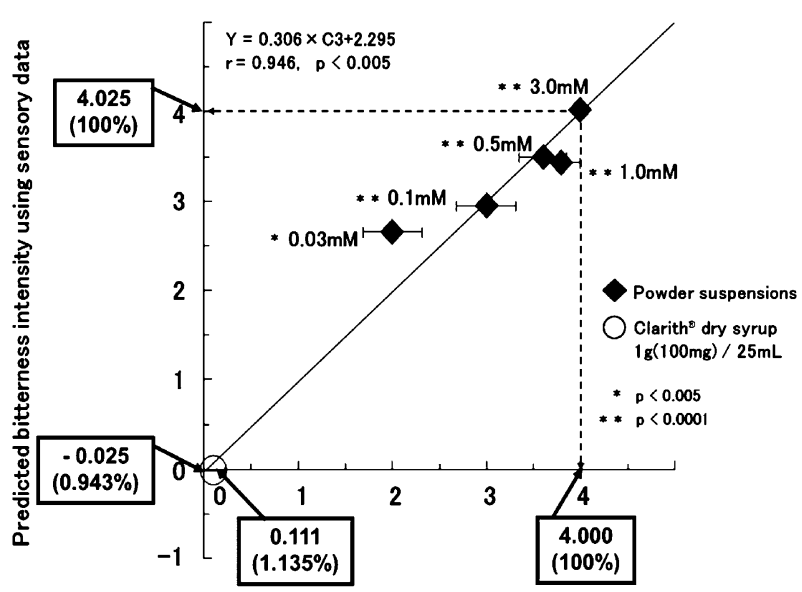

Bitterness intensity score evaluated by gustatory sensation

Fig. 3. The Relationship between Bitterness Intensity Scores Obtained in Human Gustatory Sensation Tests and the Predicted Bitterness Scores Derived from the Taste Sensor Output (CPA value of channel 3)

CPA 測定により明らかにした (Fig. 3). ${ }^{4)}$ 同ドライ シロップ製剤は，ヨーグルトや酸性スポーツ飲料と 同時服用すると，苦味が増強することが知られてい る. 製剤が存在する環境が酸性に変化すると物理的 なマスキングが施されていた製剤から薬物が溶出す ることが原因であるが，味センサ利用により，薬物 を食品・飲料と同時に服用した場合の苦味強度の変 化も予測できることを報告している. ${ }^{9)}$ またすべて の官能試験は本学倫理委員会で承認されたプロト コールを使用し，パネラーに十分試験内容を説明後 実施した。

上記の苦味の評価は, 苦味物質と苦味センサの人
工脂質膜との疎水性相互作用によるものであるが， 可塑剤の種類と配合量を最適化することで高感度型 の新規苦味センサ BT0 が開発された。データには 示していないが 8 種の $\mathrm{H}_{1}$ 抗アレルギー薬に対して 感度よく苦味評価が可能であった事実について最近 報告した. ${ }^{11)}$

2-1. アミノ酸の苦味の定量化 ${ }^{1,6)}$ につて 経 口栄養剂や肝不全用栄養剂の主成分であるアミノ酸 類は通常の薬物に比較して物質量あたりの苦味は弱 いものの，栄養剤中に含まれるような分枝鎖アミノ 酸 (branched chain amino acid; BCAA) (L-Ile：イ ソロイシン, L-Leu : ロイシン, L-Val : バリン) や芳香族アミノ酸 (L-Trp : トリプトファン, LPhe : フェニルアラニン) は比較的強い苦味がある ことが知られている.

Figure 4 には，濃度の異なる苦味アミノ酸 5 種の 単成分系溶液 $(1,3,10,30,100 \mathrm{mM}$; L-Trp $100 \mathrm{~mm}$ 溶液の夕調製不可) と $10 \mathrm{mM} \mathrm{KCl}$ 溶液の合計 25 種 の官能值とセンサの 1 チャネルの相対值との回帰式 を示した. ${ }^{1)}$ BCAA に代表される苦味アミノ酸類の 苦味評価においては，1 本の苦味応答センサの相対 值 $\mathrm{r}$ 值（先出）力值を利用することで, $\mathrm{r}^{2}=0.704$ と良好な相関性が認められた。 上記 5 種の苦味アミ ノ酸の中から 2 種の成分を選択して混合することに より得られる 10 種類の 2 成分の混合溶液について も味センサの出力值から官能值を予測したところ, $\mathrm{r}^{2}=0.776$ と良好な予測性が達成された。このよう 


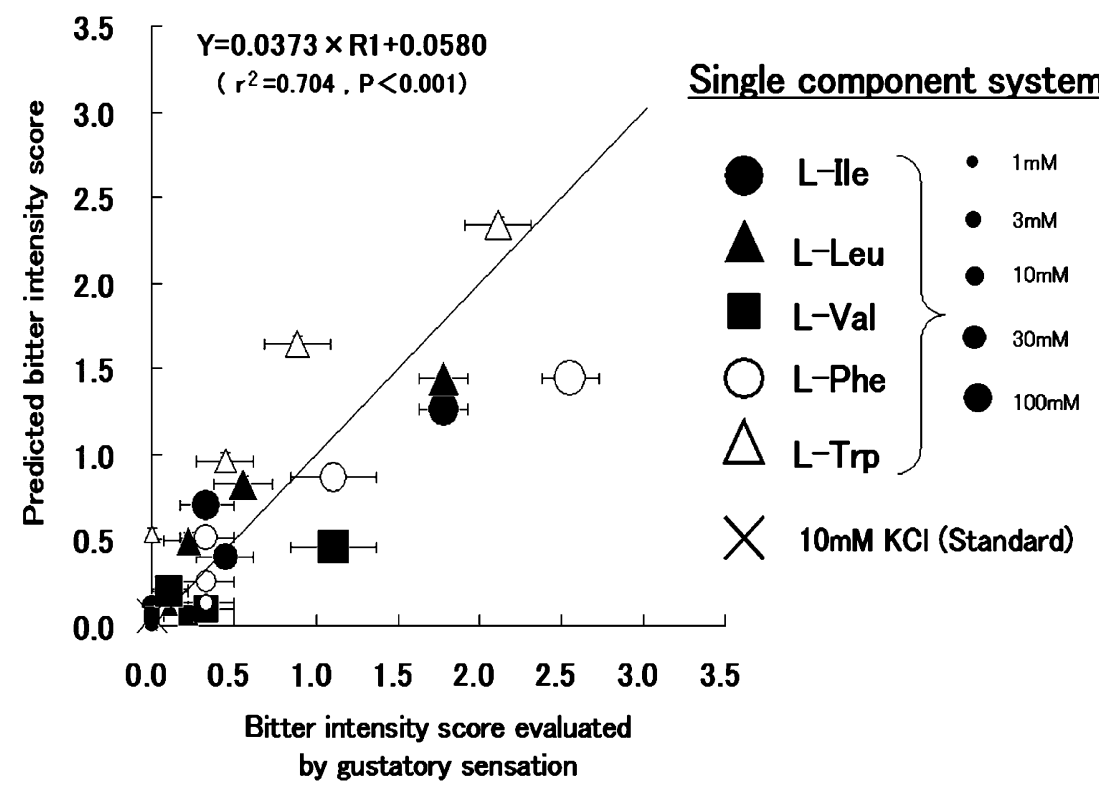

Fig. 4. Prediction of Bitterness Score for Five Different Amino Acids

に単成分系のみならず，多成分系の BCAA の混合 溶液についても 1 種類の苦味応答性のセンサの相対 值を利用することにより比較的精度よく苦味強度を 推定できることが明らかになった.

3. 電子味覚システム（アルファ・モス社）を使 用した $\mathbf{H}_{1}$ 抗ヒスタミン薬の苦味予測13)

電子味覚システム Astree II は, サンプル溶液中 の有機，無機成分に応答する広域選択性を有する 7 つのセンサを用い，あらゆる味成分の違いを検出す ることが可能である。センサは CHEMFET（化学 的電界効果トランジス夕）技術に基づく電気化学セ ンサであり，感度と選択性が最適に調整されてい る. インセント社の味認識装置とは異なり, 各セン サが単一の味に対して選択的に応答するわけではな く，7つのセンサの組み合わせによるパターンによ って味を識別している.ここでは，アルファ・モス 社の電子味覚システム Astree II を使用して, $\mathrm{H}_{1}$ 抗 ヒスタミン薬の定量的苦味予測と，人工甘味料を用 いた苦味マスキング効果予測について検討した.

3-1. $\mathbf{H}_{1}$ 抗ヒスタミン薬の主成分分析による評 価 8 種類の $\mathrm{H}_{1}$ 抗ヒスタミン薬を電子味覚シス テム Astree II で評価した. 2. での実験と同様に, セ チリジン (cetirizine; CET), ジフェンヒドラミン (diphenhydramine; DIP), クロルフェニラミン (chlorpheniramine; CHL)， エピナスチン (epinastine; EPI), ケトチフェン (ketotifen; KET), オロパタジ
ン (olopatadine; OLO), フェキソフェナジン（fexofenadine; FEX), アゼラスチン(azelastine; AZE), 及び標準苦味物質であるキニーネ (quinine; QUI) を使用した，薬物の苦味情報をより正確に評価する ため, デー夕解析に使用するセンサの最適化を実施 した。様々なセンサの組み合わせを検討した結果, 最終的に 2 本のセンサを使用した主成分分析が薬物 の味を最も正確に表現していると考えられた。

Figure 5 (A) に各薬物の苦味スコア（官能試験デー 夕）と酸味スコア（pH）をプロットした 2 次元の Taste map を, Fig. 5(B)に 2 本のセンサから得た デー夕を使用した主成分分析結果を示した.

主成分分析の $\mathrm{PC} 1$ と $\mathrm{PC} 2$ をそれぞれ酸味と苦味 であると解釈すれば，この結果は薬物の Taste map [Fig. 5(A) ] とよく一致しており, 酸味と苦味を表 現していると考えられた。図からセチリジンは苦味 強度が弱く，酸味が最も強いことが明らかである.

3-2. 人工甘味料を用いたエピナスチンの苦味マ スキング効果の予測インセント社の味認識装置 では，ACK（アセスルファムカリウム）による苦 味マスキング効果の予測が可能であったが，センサ 応答のない ASP（アスパルテーム）を使用した場 合は評価できない。そこで，本節ではアルファ・モ ス社の電子味覚システム Astree II を使用した人工 甘味料（ASP 0.015, 0.05, 0.15 mg/mL; ACK 0.015, $0.05,0.15 \mathrm{mg} / \mathrm{mL}$ ) を 3 段階濃度で添加した試料 
(A)

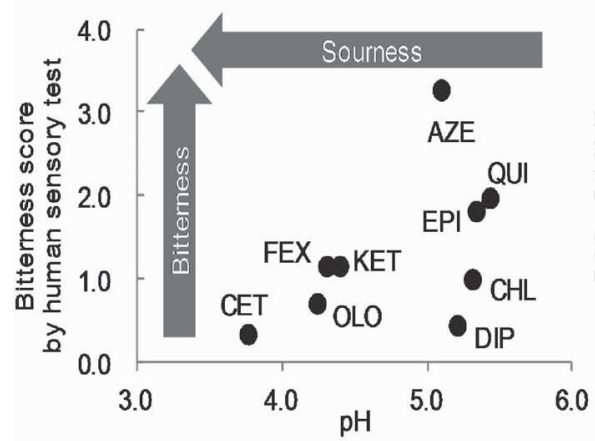

(B)

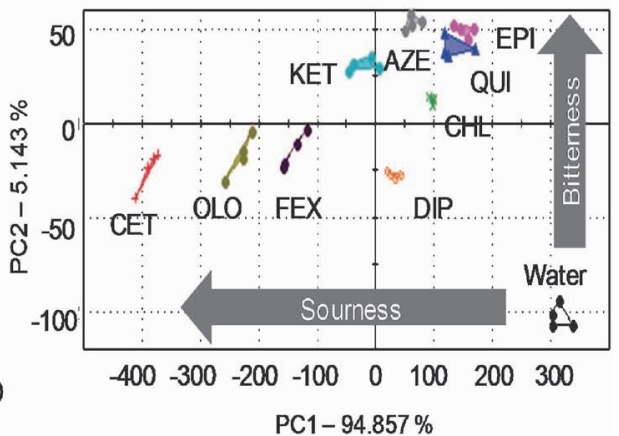

Fig. 5. A: 2-D Map Using the Bitterness and Sourness of the Eight $\mathrm{H}_{1}$-antihistamines (0.1 mM), and B: Principal Component Analysis of the Eight $\mathrm{H}_{1}$-antihistamines and Quinine Hydrochloride $(0.03 \mathrm{mg} / \mathrm{mL})$ Using Two Sensors

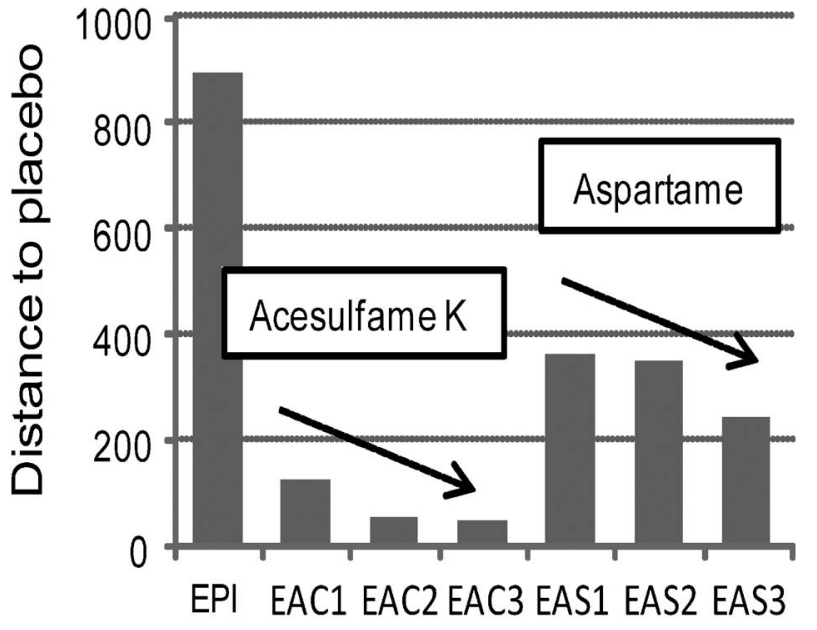

Fig. 6. Euclidean Distance between the Active Sample Solution Containing Epinastine Hydrochloride and Its Placebo Sample Solution (A to P distance)

(Fig. 6 中の EAS1, EAS2, EAS3, 並びに EAC1, $\mathrm{EAC} 2, \mathrm{EAC} 3$ に相当）の苦味マスキング効果の予 測方法について評価した。モデル薬物にはエピナス チン（0.1 mM）を用いた.

3-3. 主成分分析によるエピナスチンの苦味マス キング効果の評価（A-P 距離を用いた予測モデル 又は $\mathbf{A}-\mathbf{A}$ 距離を用いた予測モデル）電子味覚 システムから得た各サンプル溶液のデータを主成分 分析した結果, 各サンプルは甘味料の濃度及び種類 に応じてよく識別されており，甘味料なしのグルー プ，ACK のグループ，及び ASP のグループに分け ることができた。苦味マスキング効果の評価には, アクティブサンプル（薬物を含む溶液）とそれに対 応するプラセボサンプルとの距離（A-P 距離）を 使用した。通常，よくマスキングされているサンプ
ルはそのプラセボと距離が近い（味が似ている）と いう仮定を設けている. Figure 6 に全サンプルのA $-\mathrm{P}$ 距離を示す。エピナスチン単独の $0.1 \mathrm{mM}$ 水溶 液（EPI）の A-P 距離は 890 であり, 強い苦味を 有していることを表している。このサンプルに ACK を 3 段階濃度 $(0.015,0.05,0.15 \mathrm{mg} / \mathrm{mL})$ で 添加した試料（図中 $\mathrm{EAC} 1, \mathrm{EAC} 2, \mathrm{EAC} 3$ に相当） を加えた場合，大きな距離の減少がみられ，0.015 $\mathrm{mg} / \mathrm{mL}$ の ACK (EAC1: A-P 距離 : 121) でも 86.4\%のマスキング効果を達成していると予測され, $0.15 \mathrm{mg} / \mathrm{mL}$ の ACK 添加 (EAC3: A-P 距離 : 40) では $95.5 \%$ のスキングを達成していると考えら れた。一方 ASP を加えた場合, $0.15 \mathrm{mg} / \mathrm{mL}$ の ASP 添加（EAS3：A-P 距離：236） で 73.5\%のマスキン グ効果であった。これらの結果から, エピナスチン に対しては ACK の方が ASP より苦味マスキング 効果は高いと推測された.

別の評価方法として，アクティブサンプル（薬物 と甘味料を含む溶液）と甘味料を含まない薬物単独 の溶液との距離（A-A 距離）を使用した評価を実 施したが，この $\mathrm{A}-\mathrm{A}$ 距離も苦味スコアと非常によ い相関（ $\mathrm{r}^{2}=0.9891 ） を$ 示した. エピナスチンの苦 味マスキングに ACK を用いた場合, 上記いずれの 苦味予測モデルでも高い精度での予測が可能である ことが示唆された。

4. センサによるベシケア ${ }^{\circledR} O D$ 錠粉砕が苦味強 度に及ばす影響

近年発売されたベシケア ${ }^{\circledR} \mathrm{OD}$ 錠は，薬物を含む 微粒子表面に精密なコーティングが施され，口腔内 での薬物の初期溶出を抑えた設計となっている。従 
来のベシケア®錠は小児の用量調整のために粉砕し て用いられることがあり，錠剤粉砕時の苦味が服用 時の問題であった，本検討ではベシケア®錠，ベシ ケア ${ }^{\circledR} \mathrm{OD}$ 錠を粉砕した場合の苦味を，味覚センサ を用いて予測することを目的とした。すすおち、べ シケア ${ }^{\circledR}$ 錠，ベシケア ${ }^{\circledR} \mathrm{OD}$ 錠を，乳鉢・乳棒を用い て細かく粉砕した試料（粒子径 $100 \mu \mathrm{m}$ 以下）と， 薬包紙上で乳棒を用いて粗く粉砕した試料（粒子径 $100 \mu \mathrm{m}$ 以上 $500 \mu \mathrm{m}$ 未満）を調製した。粉砕試料 5 $\mathrm{mg}$ （成分量）を入れたバスケットを， $40 \mathrm{~mL}$ の精製 水 $\left(37^{\circ} \mathrm{C}\right)$ を入れたビーカーに入れ，25 rpm で振 とうし，5，10，30，60，90，120 秒後にバスケットを 取り出し, 直ちに吸引濾過した。 万液を味覚センサ, HPLC 法を用いて測定した.

脂質膜センサを用いて苦味強度を測定した結果, ベシケア®錠は，粉砕の程度にかかわらず，溶出試 験開始 5 秒後には苦味強度約 $\tau 3$ を示すことが予測 された。ベシケア ${ }^{\circledR} \mathrm{OD}$ 錠を細かく粉砕した試料 は, ベシケア®錠を粉砕した試料と同程度の苦味強 度を示した。一方，ベシケア ${ }^{\circledR} \mathrm{OD}$ 錠を粗く粉砕し た試料は, 30 秒後までは $\tau 1$ 未満, 120 秒後でも $\tau 2$ 未満の苦味を呈すことが予測された（Fig. 7). ${ }^{14)}$ HPLC 法で薬物溶出濃度を測定した結果, ベシケ ア ${ }^{\circledR} \mathrm{OD}$ 錠を細かく粉砕した試料は，5秒後で既に 約 90\%の溶出を示した。一方，粗く粉砕した試料 は，120 秒後でも $20 \%$ 未満の溶出を示し，粉砕程度 が粗い場合は薬物の初期溶出の抑制が保たれること が明らかとなった。溶出液中の薬物濃度から推定さ れる苦味強度と味覚センサで予測した苦味強度はほ

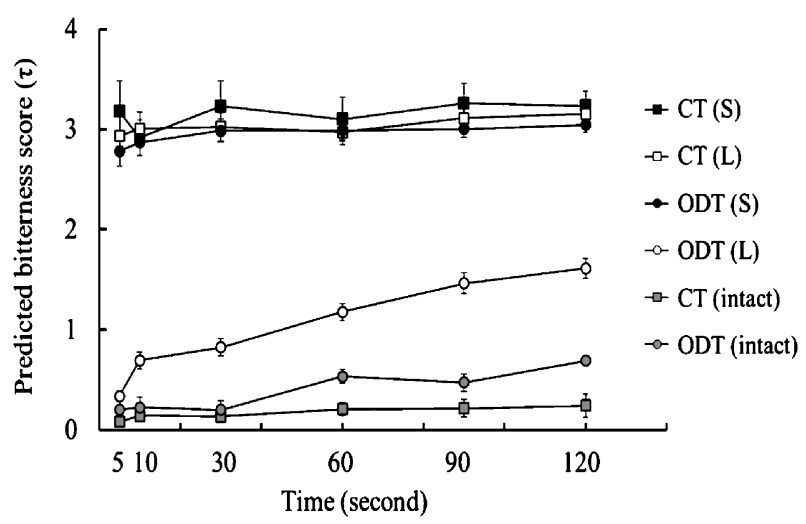

Fig. 7. Predicted Bitterness Intensity $(\tau)$ of Vesicare ${ }^{\circledR}$ CT (intact), ODT (intact), CT crushed strongly (CT (S)), CT crushed lightly (CT (L)), ODT crushed strongly (ODT (S)), ODT crushed lightly (ODT (L)).
ぼ一致した，以上の結果より，止むを得ずベシケ $ア^{\circledR} \mathrm{OD}$ 錠を粉砕する場合は，苦味に影響する粉砕 の程度に十分留意すべきであることが示唆された.

口腔内崩壊錠の服用性の評価方法としては，口腔 内崩壊錠用の崩壊試験器と味覚センサを組み合わせ ることにより，口腔内崩壊錠の口腔内における経時 的な苦味マスキング効果を評価する方法が考案さ れ，その有用性が報告されている. ${ }^{15,16)}$

5. おわりに

味センサは，食品分野は言うに及ばす，製薬企業 への導入も進んでいる。すべての医薬品の味の定量 化を完璧にできるわけでないが，センサ膜の高感度 化や新しい膜の開発が進んでいる。味の定量化，パ ターン化などユーティリティの工夫も進んでいる. 医薬品の味を正確に計測できる日も遠くないかもし れない。

謝辞 $\mathrm{H}_{1}$ 抗ヒスタミン薬の研究にご尽力を頂 いた日本ベーリンガーインゲルハイム秼製剤研究所 伊藤正紀博士に深謝します。

\section{REFERENCES}

1) Miyanaga Y., Tanigake A., Nakamura T., Kobayashi Y., Ikezaki H., Taniguchi A., Matsuyama K., Uchida T., Int. J. Pharm., 248, 207-218 (2002) .

2) Miyanaga Y., Kobayashi Y., Ikezaki H., Taniguchi A., Uchida T., Sensors and Materials, 14, 455-465 (2002).

3) Uchida T., Tanigake A., Miyanaga Y., Matsuyama K., Kunimoto M., Kobayashi Y., Ikezaki H., Taniguchi A., J. Pharm. Pharmacol., 55, 1479-1485 (2003).

4) Tanigake A., Miyanaga Y., Nakamura T., Tsuji E., Matsuyama K., Kunitomo M., Uchida T., Chem. Pharm. Bull., 51, 1241-1245 (2003).

5) Miyanaga Y., Inoue N., Ohnishi A., Fujisawa E., Yamaguchi M., Uchida T., Pharm. Res., 20, 1932-1938 (2003).

6) Ogawa T., Nakamura T., Tsuji E., Miyanaga Y., Nakagawa H., Hirabayashi H., Uchida T., Chem. Pharm. Bull., 52, 172-177 (2004).

7) Miyanaga Y., Mukai J., Mukai T., Odomi M., Uchida T., Chem. Pharm. Bull., 52, 490-493 (2004). 
8) Kataoka M., Yoshida K., Miyanaga Y., Tsuji E., Tokuyama E., Uchida T., Int. J. Pharm., 305, 13-21 (2005).

9) Ishizaka T., Okada S., Takemoto E., Tokuyama E., Tsuji E., Mukai J., Uchida T., Chem. Pharm. Bull., 55, 1452-1457 (2007).

10) Kataoka M., Tokuyama E., Miyanaga Y., Uchida T., Int. J. Pharm., 351, 36-44 (2008).

11) Ito M., Yoshida M., Kobayashi Y., Hiraoka M., Ikezaki H., Uchida T., Sensors and Materials, 23, 483-492 (2011).

12) Ito M., Wada K., Yoshida M., Hazekawa M., Abe K., Chen R., Habara M., Ikezaki H., Uchida T., Sensor and Materials, 25, 17-30
(2013).

13) Ito M., Ikehama K., Yoshida K., Haraguchi T., Yoshida M., Wada K., Uchida T., Int. J. Pharm., 441, 121-127 (2013).

14) Haraguchi T., Miyazaki A., Yoshida M., Uchida T., J. Pharm. Pharmacol., 65, 980987 (2013).

15) Harada T., Uchida T., Yoshida M., Kobayashi Y., Narazaki R., Ohwaki T., Chem. Pharm. Bull., 58, 1009-1014 (2010) .

16) Harada T., Narazaki R., Ohwaki T., Uchida T., J. Drug Del. Sci. Tech., 20, 377-383 (2010). 